\title{
A Comparative Randomised Clinical Study Between Nebulised Fentanyl and Intravenous Fentanyl For Post Operative Pain Relief
}

\author{
Lt Col Reza Ershad ${ }^{1}$, Md Mozaffer Hossain², Col Mohammad Shafiqul Alam ${ }^{3}$, \\ AKM Asaduzzaman ${ }^{4}$
} ${ }^{1}$ Classified Specialist in Anaesthesiology, Combined Military Hospital, Comilla Cantonment, ${ }^{2}$ Associate Professor, Department
of Anaeshesia, Dhaka Medical College, ${ }^{3}$ Classified specialist in Surgery (Ortho), Combined Military Hospital Dhaka, ${ }^{4}$ Classified
Specialist in Otolaryngology, Combined Military Hospital Comilla Cantonment

Corresponding author: Lt Col Reza Ershad, Classified Specialist in Anaesthesiology, Combined Military Hospital, Comilla Cantonment

\begin{abstract}
Background and Aim: Intravenous (IV) route for fentanyl administration is very effective for postoperative pain relief, but complications such as respiratory depression, bradycardia and hypotension have limited this route. The aim of this randomised clinical trial was to compare the efficacy of nebulised fentanyl with IV fentanyl for post-operative pain relief after lower abdominal surgery. Methods:In the post-operative wards, at the time of first onset of pain (visual analogue scale-VAS score >5) patients were randomised into two groups and either fentanyl IV $2 \mu \mathrm{g} / \mathrm{kg}$ or by nebulisation of solution containing 4 $\mu \mathrm{g} / \mathrm{kg}$ fentanyl over $6-8 \mathrm{~min}$ in 120 patients divided into two groups of 60 each. Observation were made for pain relief by visual analogue scale score 0-10. Adverse effects such as respiratory depression, bradycardia and hypotension were also recorded. Statistical analysis was performed using Medcalc software version 12, 2012. (MedCalc Software, Ostend, Belgium). Results: In the nebulisation group, it was observed that the analgesic efficacy of fentanyl had little delayed onset $(10 \mathrm{~min}$ vs. $5 \mathrm{~min}$ ). Nebulisation with $4 \mu \mathrm{g} / \mathrm{kg}$ fentanyl produced analgesia at par to $2 \mu \mathrm{g} / \mathrm{kg} I V$ fentanyl with prolonged duration (90 min vs. $30 \mathrm{~min}$ ) and with significantly less adverse effects. Conclusions:This study shows that nebulisation with $4 \mu \mathrm{g} / \mathrm{kg}$ fentanyl may be used as an alternative to IV $2 \mathrm{ig} / \mathrm{kg}$ fentanyl for adequate post-operative pain relief.
\end{abstract}

Key words: Fentanyl, post-operative analgesia, pulmonary administration, side-effects.

(JBSA 2014; 27(1): 27-30)

\section{Introduction}

Adequate post operative pain relief has always been great concern for Anaesthesiologists and Surgeons.In this regard intravenous fenatanyl is very effective. However, it is often associated with complications such as respiratory depression, bradycardia and hypotension. The alternative route could be pulmonary drug delivery. Fentanyl being highly lipophilic is suitable for use through this route and pulmonary administration could be a new promising non invasive method for systemic fentanyl administration. Further it has been observed that on inhalation, fentanyl is absorbed rapidly and reaches maximum serum level approximately in $2 \mathrm{~min}$. Few studies have shown significant post operative pain relief with nebulised fentanyl. ${ }^{2-4}$ Chrubasik et al. reported that morphine nebulisation was as effective as IV morphine for pain relief after abdominal surgery. ${ }^{5}$ Thus, the aim of this study was to compare the analgesic efficacy of nebulised fentanyl with IV fentanyl for postoperative pain relief in lower abdominal surgery.

\section{Methods}

This prospective randomised clinical trial was conducted by the Department of Anaesthesiology in collaboration with the Department of Orthopedics in the Combined Military Hospital Comilla between March 2013 to January 2014. It was approved by the Institutes Review Board and Ethical Committee. An informed written consent was taken from all the patients included in the study. 120 ASA Grade I or II patients of either gender between 20 and 40 years of age scheduled for lower abdominal surgery under regional 
anaesthesia were able to comprehend assessment scales after due explanation were selected for study. Pregnant or breast feeding women, patients with morbid obesity, respiratory, hepatic and renal insufficiency, addiction or hypersensitivity to opioids were excluded from the study. Those already on chronic analgesic use and those not consenting for the study were excluded from the study. There were two study groups: IV fentanyl group A and nebulisation group B . Patients underwent 60-90 min of surgery under spinal anaesthesia with $12.5 \mathrm{mg}$ Bupivacaine under sedation by iv midazolam perioperatively.

Power of study was kept $80 \%$, level of significance $5 \%$. Efficacy of Fentanyl was considered $100 \%$ by IV route and in nebulisation group it was taken as $75 \%$. With above consideration sample size came out 52 patients in each group by taking ratio 1:1. Assuming treatment failure rate of $15 \%$ in nebulisation group, sample size was kept at 60 . $(52+8)$ in each group. On arrival of the patients in post operative ward,two paramedics alternately allocated patients included in the study into two groups (A \& B).Fentanyl solution was prepared by paramedics as $4 \mathrm{ml}$ for iv and $5 \mathrm{ml}$ for nebulization. The quantity was $1 \mathrm{ml}$ more for the nebulised group to compensate for the loss of the drug through the ventimask during nebulisation and in the upper airway.Group A received the iv fentanyl and group $B$ received the nebulised fentanyl whenever the patient complained of pain for the first time of visual analogue scale(VAS) score $>5$.

The paramedics filled up questioneries supplied to them according to the patients statements regarding pain relief. Concentration of fentanyl was kept as $2 \mu \mathrm{g} / \mathrm{kg}$ in iv solution in group A and 4 $\mu \mathrm{g} / \mathrm{kg}$ in group B. Patients were nebulised by a standard ventimask having nebulisation chamber at a constant flow rate of oxygen $-10 \mathrm{l} / \mathrm{min}$ for 6 - 8 min. After completion of nebulisation, onset time of analgesia was calculated in nebulisation group. Upon further complaint of pain with VAS score $>5$, analgesia was provided by the second paramedic of routine posting as per unit protocol. Patients who were not relieved of pain even after 15 min from start of study, received IV ketorolac and were excluded from the study.

Patients were observed continuously and data was recorded initially at 5,10 and $15 \mathrm{~min}$ then at interval of $15 \mathrm{~min}$ up to $1 \mathrm{~h}$ and at $30 \mathrm{~min}$ interval until completion of study. Patients were assessed for pain by VAS (0 - no pain, 10 - maximum imaginable pain), sedation by Ramsay sedation scale (RSS) (1 - anxious/restless or both; 2 cooperative, oriented and tranquil responding to command; 3 - brisk response to stimulus; 4 sluggish response to stimulus; 5 - no response to any stimulus). Patients were observed for nausea vomiting,(0-no symptoms; 1 -nausea,i.e.subjective unpleasant sensation with awareness of urgeness to vomit; 2 - retching, i.e. spasmodic contraction of oesophagus, abdominal wall and diaphragmatic muscle without expulsion of gastric content; 3vomitting i.e. forceful contraction of gastric content) heart rate,respiratory rate,non invasive blood pressure, oxygen saturation and pruritus.

The data obtained were statistically analysed by student t- test using Medcalc software version 12,2012 . $\mathrm{P}<0.05$ was considered to be statistically significant.

Primary objective :To assess the analgesic efficacy of nebulised fentanyl in comparison to IV fentanyl for post operative pain relieve after lower abdominal surgery.

Secondary objective: To observe the side effects of nebulised fentanyl administered to the patient.

\section{Results}

120 patients were enrolled in the study. The enrolled were randomly divided into two groups group A and group B with 60 patients in each group. (group A received IV fentanyl and group B received nebulised fentanyl). Of the 120 patients enrolled in the study, data of 104 patients were available for analysis, 52 received nebulised fentanyl and 52 received IV fentanyl. The groups were similar in terms of demographics. The mean age of patients among all the groups were comparable and the difference not statistically significant. The distribution of males to females ranged from $40 \%$ to $60 \%$, which had no statistical significance [Table I]. Statistically significant mean VAS change started at 5 min and continued until $15 \min (\mathrm{P}<0.005)$ [Table II]. VAS decreased until 30 min in group A and until 90 min in group B. In group $\mathrm{A}$, sedation score was maximum at $5 \mathrm{~min}$. In group $\mathrm{B}$, there was a slow rise in the sedation score but it was always less than in group A [Table III]. Adverse effects in group B were less compared with the group A though statistically insignificant [Table IV]. No enrolled patient had clinically significant hemodynamic instability or respiratory depression.

Table I Demographic data of the patients 


\begin{tabular}{lccccc}
\hline Group & $\begin{array}{c}\text { Age (Years) } \\
(\text { Means+SD) }\end{array}$ & $\begin{array}{c}\text { Weight } \\
(\mathrm{kg})\end{array}$ & Male & Female & P Value \\
\hline $\mathrm{A}(\mathrm{n}=52)$ & $37.15+10.23$ & $55.5+2.44$ & 32 & 20 & NS \\
$\mathrm{B}(\mathrm{n}=52)$ & $35.81+9.15$ & $55.56+2.14$ & 33 & 19 & NS \\
\hline
\end{tabular}

Group -A (IV fentanyl $2 \mu \mathrm{g} / \mathrm{kg}$ ), Group B- (fentanyl nebulisation group $4 \mu \mathrm{g} / \mathrm{kg}$ ), NS- Not significant ( $p>0.05)$ : SD- Standard deviation: IV- Intravenous.

Table II Changes in mean VAS

\begin{tabular}{lccc}
\hline $\begin{array}{l}\text { Time interval } \\
(\mathrm{min})\end{array}$ & $\begin{array}{c}\text { Group A } \\
(\mathrm{n}=52)\end{array}$ & $\begin{array}{c}\text { Group B } \\
(\mathrm{n}=52)\end{array}$ & $\begin{array}{c}\text { P } \\
\text { Value }\end{array}$ \\
\hline 5 & $5.80 \pm 1.136$ & $0.20 \pm 0.632$ & 0.002 \\
10 & $1.00 \pm 0.824$ & $2.60 \pm 0.632$ & 0.001 \\
15 & $0.20 \pm 0.632$ & $3.80 \pm 0.632$ & 0.001 \\
30 & $0.04 \pm 1.398$ & $1.80 \pm 1.136$ & 0.07 \\
45 & $3.70 \pm 2.674$ & $1.60 \pm 1.414$ & 0.04 \\
60 & $\mathrm{NA}$ & $0.80 \pm 0.52$ & - \\
90 & $\mathrm{NA}$ & $1.80 \pm 2.674$ & - \\
120 & $\mathrm{NA}$ & $3.20 \pm 2.530$ & - \\
\hline
\end{tabular}

NA - Not available; Group -A (IV fentanyl $2 \mu \mathrm{g} / \mathrm{kg}$ ), Group B- (fentanyl nebulisation $4 \mu \mathrm{g} / \mathrm{kg}$ );

VAS- Visual analogue scale;IV- Intravenous

Table III Ramsay sedation score during study.

\begin{tabular}{lccc}
\hline $\begin{array}{l}\text { Time interval } \\
(\mathrm{min})\end{array}$ & $\begin{array}{c}\text { Group A } \\
(\mathrm{n}=52)\end{array}$ & $\begin{array}{c}\text { Group B } \\
(\mathrm{n}=52)\end{array}$ & $\begin{array}{c}\text { P } \\
\text { Value }\end{array}$ \\
\hline 0 & $3.00 \pm 1.054$ & $2.80 \pm 1.032$ & 0.965 \\
5 & $5.60 \pm 0.844$ & $3.00 \pm 1.054$ & 0.001 \\
10 & $5.60 \pm 0.844$ & $3.60 \pm 1.032$ & 0.001 \\
15 & $4.40 \pm 0.844$ & $4.00 \pm 1.032$ & 0.001 \\
30 & $4.22 \pm 0.666$ & $4.60 \pm 0.966$ & 0.310 \\
45 & $4.20 \pm 0.844$ & $4.80 \pm 1.032$ & 0.01 \\
60 & $4.32 \pm 1.032$ & $4.60 \pm 0.632$ & 0.069 \\
90 & $4.00 \pm 1.054$ & $4.00 \pm 0.966$ & 0.074 \\
120 & $2.80 \pm 1.032$ & $2.80 \pm 0.966$ & 0.054 \\
\hline
\end{tabular}

Group -A (IV fentanyl $2 \mu \mathrm{g} / \mathrm{kg}$ ),

Group B- (fentanyl nebulisation $4 \mu \mathrm{g} / \mathrm{kg}$ );

IV- Intravenous.

TableIV Incidence of adverse effect in various groups

\begin{tabular}{lccccc}
\hline Complications & \multicolumn{2}{c}{$\begin{array}{c}\text { Group A } \\
(\mathrm{n}=52)\end{array}$} & \multicolumn{2}{c}{ Group B } & P \\
& $\mathrm{No}=52)$ & Value \\
& 5 & 9.61 & 1 & 1.92 & $\mathrm{NS}$ \\
PONV & 4 & 7.69 & 3 & 5.77 & $\mathrm{NS}$ \\
Pruritus & 0 & 0 & 0 & 0 & $\mathrm{NS}$ \\
Hypoxia & 0 & 0 & 0 & 0 & $\mathrm{NS}$ \\
Urinary retention & 0 & 0 & 0 & 0 & $\mathrm{NS}$ \\
Bradycardia & 0 &
\end{tabular}

PONV- Post-operative nausea and vomiting; Group -A (IV fentanyl $2 \mu \mathrm{g} / \mathrm{kg}$ ), Group B- (fentanyl nebulisation group $4 \mu \mathrm{g} / \mathrm{kg}$ ), NS- Not significant ( $>>0.05$ ).

\section{Discussion}

The intension of this study was to compare the different clinical approaches, for patients benefit in postoperative pain relief. In this study patients who were operated by General Anaesthesia were excluded to avoid emergence delirium effect of general anaesthesia. Patients were nebulised with fentanyl post operatively at onset of pain as few studies suggested that nebulised fentanyl has a good analgesic efficacy. ${ }^{2-4}$ Patients in the nebulisation group B were nebulised with fentanyl $4 \mu \mathrm{g} / \mathrm{kg}$ compared with IV fentanyl $2 \mu \mathrm{g} / \mathrm{kg}$ in group A considering wastage of drug in nebulisation chamber and upper airway.

In our study, onset of analgesia was delayed in the nebulisation group (10 min vs. 5 min) which correlates with the finding of the previous studies that maximum serum concentration of fentanyl was reached at 13 min after intranasal administration as compared to IV administration ${ }^{6}$ (2-3 min), but contradicts the finding of Mather ${ }^{7}$ who reported that inhaled fentanyl reached to therapeutic level in blood stream as quickly as IV dosing. This needs further evaluation. 
Quality of analgesia evidenced by change in VAS was noted after nebulisation by $4 \mu \mathrm{g} / \mathrm{kg}$ fentanyl, it was equivalent to $2 \mu \mathrm{g} / \mathrm{kg}$ IV fentanyl. The duration of pain relief in nebulisation group was prolonged (90 min vs. $30 \mathrm{~min}$ ). RSS in group A reached peak at 5 min and decreased after $1 \mathrm{~h}$. In nebulisation group, it increased after $10 \mathrm{~min}$ but was always less than iv group during study. This finding can be attributed to slow rise in peak plasma concentration by inhalational administration of fentanyl. This correlates with the finding by previous studies that maximum serum concentration of fentanyl is reached at 13 min after intranasal administration as compared to IV administration (2-3 min). ${ }^{6}$

No major adverse effects like respiratory depression; hypoxia or bronchospasm was observed in both groups. This correlates with the finding by Worsely ${ }^{1}$ and Higgins ${ }^{8}$. Side-effects such as pruritus, nausea and vomiting were observed in both groups.

In the present study, the oxygen saturation was comparable in both groups and was statistically non significant $(P>0.05)$. We observed stable heart rate, blood pressure, respiratory rate in nebulisation group when compared with iv group. This finding can be attributed to slow rise in peak plasma concentration by inhalational administration of fentanyl. Overall, as a primary outcome of the study it revealed a delayed onset of analgesia in patients on nebulised fentanyl 4 $\mu \mathrm{g} / \mathrm{kg}$ compared to IV fentanyl 2 micro $\mu \mathrm{g} / \mathrm{kg}$ (10 min vs. $5 \mathrm{~min}$ ) but the effect was prolonged (90 min vs. $30 \mathrm{~min}$ ). The quality of analgesia with nebulised fentanyl $4 \mu \mathrm{g} / \mathrm{kg}$ was found equivalent to the control group of patients with IV fentanyl 2 $\mu \mathrm{g} / \mathrm{kg}$. As a secondary outcome, measure of the side effects of the drug were found to be minimal in the nebulised group. However, there are certain limitations of this study. As we were evaluating efficacy of nebulised fentanyl we have not evaluated total consumption of fentanyl in $24 \mathrm{~h}$ by nebulisation route considering it as sole analgesic. The present study included only patients who underwent lower abdominal surgery under spinal anaesthesia. However, the usefulness of inhaled fentanyl is limited as there are many situations such as head and neck surgery, patients with orofacial trauma, uncooperative and agitated patients where inhaled fentanyl administration is difficult/impossible.

\section{Conclusions}

Considering the benefit of the patients this trial gives promising results. It showed that post operatively $4 \mu \mathrm{g} / \mathrm{kg}$ nebulised fentanyl produces comparable pain relief to $2 \mu \mathrm{g} / \mathrm{kg}$ iv fentanyl for a longer duration and with minimal side effects. This study opens new horizon for further work on nebulisation of fentanyl as an alternative noninvasive method of analgesia.

\section{References}

1. Worsley MH, MacLeod AD, Brodie MJ, Asbury AJ, Clark C. Inhaled fentanyl as a method of analgesia. Anaesthesia 1990;45:449-51.

2. Bartfield JM, FlintRD, McErlean M, Broderick J. Nebulized fentanyl for relief of abdominal pain. Acad Emerg Med 2003;10:215-8.

3. Furyk JS, Grabowski WJ, Black LH. Nebulized fentanyl versus intravenous morphine in children with suspected limb fractures in the emergency department: A randomized controlled trial. Emerg Med Australas 2009; 21: 203-9.

4. Miner JR, Kletti C, Herold M, Hubbard D, Biros MH. Randomized clinical trial of nebulized fentanyl citrate versus i.v. fentanyl citrate in children presenting to the emergency department with acute pain. Acad Emerg Med 2007;14:895-8.

5. Chrubasik J, Geller E, Niv D, Zindler M. Morphine inhalation versus intravenous infusion in pain treatment after abdominal surgery. Anesth Analg 1987;66:29.

6. Kissiu I. Preemptive analgesia. Anesthesiology 2000; 93: 1138-43.

7. Mather LE, Woodhouse A, Ward ME, Farr SJ, Rubsamen RA, Eltherington LG. Pulmonary administration of aerosolised fentanyl: Pharmacokinetic analysis of systemic delivery. Br J Clin Pharmacol 1998;46:37-43.

8. Higgins MJ, Asbury AJ, Brodie MJ. Inhaled nebulised fentanyl for postoperative analgesia. Anaesthesia 1991;46:973-6. 